\title{
Predictive value of death certification in the case ascertainment of epilepsy
}

\author{
G S Bell, A Gaitatzis, A L Johnson, J W Sander
}

J Neurol Neurosurg Psychiatry 2004;75:1756-1758. doi: 10.1136/jnnp.2003.029918

Objectives: Death certificates are an unreliable source of information on cause of death, and mortality due to epilepsy can thus be underestimated.

Methods: We investigated people with epilepsy who had died, and attempted to identify factors that influence inclusion of epilepsy on the death certificate; eight factors were hypothesised and entered into a univariate logistic regression model.

Results: Epilepsy was on the death certificate of 16/243 (7\%) people who had had epilepsy. Factors that influenced whether or not epilepsy appeared on the certificate were seizure frequency, antiepileptic drug treatment, cause of death, and certifying physician. Factors that did not seem to influence the inclusion of epilepsy were presence of convulsive seizures, occurrence of seizures during follow up, and age at death.

Conclusions: We have estimated the degree of unreliability of death certificates (as currently used in the UK) as a source of information on cause of death in epilepsy. We have found that epilepsy may not appear on death certificates even if people had active epilepsy.

$\mathrm{S}$ tudy of the mortality of epilepsy is affected by methodological difficulties. One common source of case ascertainment, death certificates (DCs), can be an unreliable source of information on cause of death. ${ }^{12}$ While it is recognised that reliance on DCs will underestimate the mortality of epilepsy, the extent of the underestimation is unknown. We used data from the National General Practice Study of Epilepsy (NGPSE) to investigate the number of people with epilepsy who died that would be captured using DCs. We also attempted to identify factors that influence inclusion of the word "epilepsy" in the certification.

\section{METHODS}

The NGPSE has been described elsewhere. ${ }^{3-5}$ It is a prospective general population based cohort study of people with newly diagnosed seizures; it recruited subjects from 1984 until 1987, and has accrued over 7000 patient-years of observation (censored for deaths). Patients were followed from an index seizure to death or to early 2000. Patients were classified 6 months after study entry as having either definite epilepsy (564) or possible epilepsy (228). Throughout the study, follow up forms were sent to relevant GPs and hospital specialists, and details requested of seizure status, medical conditions, and treatment. The National Health Service Central Register flagged the cohort, and routinely copied DCs to the study.

Follow up forms were examined to establish whether subjects had ever had convulsive seizures, and whether they had further seizures during the study. The average number of seizures/year during the last 5 years before death (or during lifetime, after onset, where shorter) was calculated. DCs were examined to see whether epilepsy (or seizures or status epilepticus) was mentioned. The name of the certifying physician was compared with the name of the physician who completed the most recent follow up form (current physician), and with that of the physician who registered the patient with the study (referring physician). Presumed cause of death was established from the DC and clinical information from follow up forms, and classified into three groups: malignancy, vascular (including cerebrovascular and cardiovascular deaths), and other. Other included diagnoses such as alcohol related death, respiratory illness, and congenital/ metabolic disease.

We hypothesised that the following factors might determine whether epilepsy was mentioned on the DC:

- classification into definite or possible epilepsy

- convulsive seizures

- seizures during follow up

- average number of seizures/year in the 5 years before death

- age at death

- certifying physician

- presumed cause of death

- number of antiepileptic drugs (AEDs) at last follow up.

Each of these factors was entered into a univariate logistic regression model, and results were expressed as odds ratios (and 95\% confidence interval (CI)) for epilepsy on the DC. Statistical analysis was performed using SPSS for Windows, release 11 (SPSS, Chicago, IL).

Clinical and DC information for each subject were examined to estimate whether epilepsy might be expected on the DC. This process was similar to that used for case inclusion in the National Sentinel Clinical Audit into epilepsy related deaths. ${ }^{67}$

\section{RESULTS}

There were 246 deaths during follow up. After excluding three with incomplete information, there were 181 (74\%) with definite and $62(26 \%)$ with possible epilepsy. Epilepsy was mentioned on the DC of $10(6 \%)$ with definite epilepsy and six $(10 \%)$ with possible epilepsy. Subjects with DCs, those with epilepsy mentioned, and the results of exploratory logistic regression analysis are shown in table 1 .

In 211 people it was possible to compute the average number of seizures/year. Most subjects (106; 50\%) had no seizures and the mean number of seizures/year was 15 (seizures occurring more frequently than daily were counted

Abbreviations: DC, death certificate; NGPSE, National General Practice Study of Epilepsy 


\begin{tabular}{|c|c|c|c|}
\hline & $\begin{array}{l}\text { With death } \\
\text { certificates, } \\
\text { n }\end{array}$ & $\begin{array}{l}\text { With epilepsy } \\
\text { on death } \\
\text { certificate, } \mathbf{n}(\%)\end{array}$ & $\begin{array}{l}\text { Odds ratio } \\
(95 \% \mathrm{Cl})\end{array}$ \\
\hline \multicolumn{4}{|l|}{ Classification } \\
\hline Possible epilepsy & 62 & $6(10)$ & 1 \\
\hline Definite epilepsy & 181 & $10(6)$ & $0.5(0.2$ to 1.6$)$ \\
\hline \multicolumn{4}{|c|}{ Convulsive seizures } \\
\hline Yes & 175 & $14(8)$ & 1 \\
\hline No & 59 & $2(3)$ & $0.4(0.1$ to 1.8$)$ \\
\hline Not known & 9 & & \\
\hline \multicolumn{4}{|l|}{ Age at death (years) } \\
\hline$<65$ & 71 & $6(8)$ & 1 \\
\hline $65-74$ & 48 & $1(2)$ & $0.2(0.0$ to 2.0$)$ \\
\hline $75-84$ & 76 & $4(5)$ & $0.6(0.2$ to 2.2$)$ \\
\hline $85+$ & 48 & $5(10)$ & $1.3(0.4$ to 4.4$)$ \\
\hline \multicolumn{4}{|c|}{ Seizures during follow up } \\
\hline Yes & 129 & $12(9)$ & 1 \\
\hline No & 82 & $2(2)$ & $0.2(0.1$ to 1.1$)$ \\
\hline Not known & 32 & & \\
\hline \multicolumn{4}{|c|}{ Certifying physician } \\
\hline Other physician & 144 & $6(4)$ & 1 \\
\hline Current physician & 18 & $1(6)$ & $1.4(0.2$ to 12$)$ \\
\hline Referring physician & n 47 & $4(9)$ & $2.1(0.6$ to 7.9$)$ \\
\hline Coroner & 34 & $5(15)$ & $4.0(1.1$ to 14$)$ \\
\hline \multicolumn{4}{|c|}{ Average seizures/year } \\
\hline None & 106 & $4(4)$ & 1 \\
\hline $1-12$ & 87 & $7(8)$ & $2.2(0.6$ to 7.9$)$ \\
\hline More than 12 & 18 & $3(17)$ & $5.1(1.04$ to 25$)$ \\
\hline Not known & 32 & & \\
\hline \multicolumn{4}{|l|}{ Cause of death } \\
\hline Malignancy & 73 & $1(1)$ & 1 \\
\hline Vascular & 106 & $7(7)$ & $5.1(0.6$ to 42$)$ \\
\hline Other & 64 & $8(13)$ & $10.3(1.3$ to 85$)$ \\
\hline \multicolumn{4}{|c|}{ Antienilentic druas at last follow un } \\
\hline None & 97 & $1(1)$ & 1 \\
\hline Monotherapy & 122 & $13(11)$ & 11.4 (1.5 to 89$)$ \\
\hline $\begin{array}{l}\text { Polytherapy } \\
\text { Pops }\end{array}$ & 17 & $2(12)$ & $12.8(1.1$ to 150$)$ \\
\hline Not known & 7 & & \\
\hline
\end{tabular}

as 365 seizures/year). Mean age at death was 70 years and median age was 75 years (range 3-98 years).

Factors that influenced mention of epilepsy on the DC were seizure frequency, AED treatment, cause of death, and certifying physician. Review of clinical and DC information suggested that epilepsy should have been on the certificates of $105(43 \%)$ subjects.

\section{DISCUSSION}

Epilepsy was on the DC of a minority of patients even when there was a history of relatively recent seizures. The small number of DCs including epilepsy limited the analysis to exploratory univariate logistic regression, and limited the number of groups entered into each analysis.

Those with more than 12 seizures per year were more likely to have epilepsy on the certificate than those with none, but epilepsy was only recorded in 3/18 with frequent seizures. Those on AEDs were more likely to have epilepsy recorded than those not on AEDs, but were also in a small minority (15/139). There was no increased rate of reporting epilepsy by physicians who had completed the most recent follow up form and should therefore be aware of the diagnosis of epilepsy; indeed the coroner was the most likely to report epilepsy. Neither the presence of convulsive seizures nor younger age at death influenced mention of epilepsy on the certificate.

Many studies have been based on information found on DCs, ${ }^{8}{ }^{9}$ but they are an inaccurate record of cause of death in epilepsy ${ }^{10}{ }^{11}$ as well as diabetes, ${ }^{12}$ asthma, ${ }^{13}$ and cancer. ${ }^{14}$ In investigations into deaths related to epilepsy, in many cases epilepsy has not been mentioned on the DC. In a study of childhood deaths, in only $55 \%$ of deaths attributable to epilepsy was the diagnosis of epilepsy on the DC. ${ }^{15}$ A study of older people with known seizures included 11 patients who died suddenly and unexpectedly of unknown cause, and in circumstances compatible with a seizure. In only one case was epilepsy on the DC. ${ }^{16}$

There are several reasons why epilepsy may not be recorded on DCs. Death certification is not primarily intended for epidemiological research, but in the UK was instigated in 1837 as an important legal and social requirement. The Home Office, the government department responsible for internal affairs in England and Wales, initiated a review into death certification in 2001, in response to the conviction of a general practitioner for murder. This review lists nine items as including the most essential elements of death certification. As well as confirming that death has occurred, establishing the identity of the deceased person, and ensuring that unnatural deaths are properly investigated, this list includes the provision of an indication of the likely cause of death, and provision of statistical information about the cause and circumstances of the death. ${ }^{17}$ In 1978, it was suggested that in $20 \%$ of DCs there was a major discrepancy between the cause of death certified and that determined by the consultant and case notes. ${ }^{10}$ The highest proportion of major discrepancies occurred among deaths certified by the coroner. However, the errors may not have been as serious as they appeared..$^{18}$ In a more recent study senior hospital doctors were found to make more errors than juniors. ${ }^{19}$ The Home Office review suggested that the quality of death certification by doctors was uneven due to lack of training and to the low priority given to this duty. ${ }^{17}$

Under the current system of death certification in the UK, it is likely that, in many cases, the diagnosis of epilepsy is correctly absent from the certificate; the information required is that of conditions leading to death, and of other conditions contributing to death. Our results are in keeping with this, as those dying with malignancy were significantly less likely to have epilepsy on the certificate than those with other pathologies, excluding vascular. However, standardised mortality ratios (SMRs) for malignancy are increased in most studies of mortality in epilepsy. ${ }^{2021}$ CNS tumours may cause seizures, but SMRs for non-CNS tumours are also often raised. Epidemiological studies could help to establish whether this association is due to a common genetic disposition, or whether AEDs are implicated. ${ }^{22}$ Several recent government reports have made recommendations about death certification, ${ }^{23-25}$ and two of these have included provision for an account of the deceased's medical history before death. ${ }^{23} 25$ It is unclear, however, whether this information would be used for registration purposes, and unless this is so, DCs used in isolation will continue to be a poor source of information about mortality from epilepsy or other chronic diseases.

The current situation complicates efforts to conduct research into the epidemiology and causes of sudden unexpected death in epilepsy (SUDEP). The National Sentinel Clinical Audit investigated the care received by people with epilepsy who died an epilepsy related death, ${ }^{67}$ with deaths during the study period identified from DCs. The deaths identified may represent only a proportion of those who died with epilepsy, although, as most deaths from SUDEP are certified by the coroner and most patients had ongoing seizures before death, they may be more likely than others to have epilepsy on the certificate.

This study confirms that a minority of people with epilepsy would be picked up using DCs alone. Although frequent seizures, the use of AEDs, and the absence of malignancy appear to increase the appearance of epilepsy on the death 
certificate, it is still recorded in few subjects. These results are exploratory, and need to be investigated further.

The present system of death certification in the UK is not an effective way to study mortality in epilepsy. If DCs were to include important factors in the patient's clinical history, their epidemiological utility would be enhanced.

\section{ACKNOWLEDGEMENTS}

The authors would like to thank Professor David Fish and Dr Lina Nashef for helpful comments on the manuscript, and Ms Jane Hanna for help and encouragement. We also thank the National Society for Epilepsy and Epilepsy Bereaved for support.

\section{Authors' affiliations}

G S Bell, A Gaitatzis, J W Sander, Neuroepidemiology Unit, National Hospital for Neurology and Neurosurgery, University College London Hospitals NHS Trust, Queen Square, London, WCIN 3BG, UK A L Johnson, MRC Biostatistics Unit, Institute of Public Health, University Forvie Site, Robinson Way, Cambridge, CB2 2SR, UK

Competing interests: none declared

Correspondence to: Professor J W Sander, Box 29, Department of Clinical and Experimental Epilepsy, UCL Institute of Neurology, Queen Square, London, WCIN 3BG, UK; Isander@ion.ucl.ac.uk

Received 10 October 2003

In revised form 16 January 2004

Accepted 23 February 2004

\section{REFERENCES}

1 Zielinski JJ. Epilepsy and mortality rate and cause of death. Epilepsia 1974;15(2): 191-201.

2 Hauser WA, Annegers JF, Elveback LR. Mortality in patients with epilepsy. Epilepsia 1980;21(4):399-412.

3 Manford M, Hart YM, Sander JW, et al. National General Practice Study of Epilepsy (NGPSE): partial seizure patterns in a general population. Neurology 1992;42(10):1911-7.

4 Cockerell OC, Johnson AL, Sander JW, et al. Mortality from epilepsy: results from a prospective population-based study. Lancet 1994;344(8927):918-21.
5 MacDonald BK, Johnson AL, Goodridge DM, et al. Factors predicting prognosis of epilepsy after presentation with seizures. Ann Neurol 2000;48(6):833-41

6 Hanna NJ, Black M, Sander JW, et al. The National Sentinel Clinical Audit of Epilepsy-Related Death: epilepsy-death in the shadows. Norwich: The Stationery Office, 2002

7 Pedley TA, Hauser WA. Sudden death in epilepsy: a wake-up call for management. Lancet 2002;359(9320):1790-1.

8 Antoniuk SA, Oliva LV, Bruck I, et al. Sudden unexpected, unexplained death in epilepsy autopsied patients. Arq Neuropsiquiatr 2001;59(1):40-5.

9 Senanayake N, Peiris H. Mortality related to convulsive disorders in a developing country in Asia: trends over 20 years. Seizure 1995;4(4):273-7.

10 Medical Services Study Group of the Royal College of Physicians of London. Death certification and epidemiological research. BMJ 1978;2(6144):1063-5.

11 Coyle HP, Baker-Brian N, Brown SW. Coroners' autopsy reporting of sudden unexplained death in epilepsy (SUDEP) in the UK. Seizure 1994;3(4):247-54.

12 Morgan CL, Currie CJ, Peters JR. Relationship between diabetes and mortality: a population study using record linkage. Diabetes Care 2000;23(8):1 103-7.

13 Reid DW, Hendrick VJ, Aitken TC, et al. Age-dependent inaccuracy of asthma death certification in Northern England, 1991-1992. Eur Respir J 1998; 12(5): 1079-83.

14 Rigdon RH. Problems in a statistical study of disease based on death certificates. South Med J 1981;74(9):1104-6, 1111.

15 Harvey AS, Nolan T, Carlin JB. Community-based study of mortality in children with epilepsy. Epilepsia 1993;34(4):597-603.

16 Luhdorf K, Jensen LK, Plesner AM. Epilepsy in the elderly: life expectancy and causes of death. Acta Neurol Scand 1987:76(3):183-90.

17 Report of the Home Office Review of Death Certification 2001. London: The Home Office, 2001

18 Adelstein AM. Death certification and epidemiological research. BM 1978;2:1229-30

19 James DS, Bull AD. Death certification: is correct formulation of cause of death related to seniority or experience? J R Coll Phys London 1995;29(5):424-8.

20 Lhatoo SD, Johnson AL, Goodridge DM, et al. Mortality in epilepsy in the first 11 to 14 years after diagnosis: multivariate analysis of a long-term, prospective, population-based cohort. Ann Neurol 2001;49(3):336-44.

21 Nilsson L, Tomson T, Farahmand BY, et al. Cause-specific mortality in epilepsy: a cohort study of more than 9,000 patients once hospitalized for epilepsy. Epilepsia 1997;38(10):1062-8.

22 White SJ, McLean AE, Howland C. Anticonvulsant drugs and cancer. A cohort study in patients with severe epilepsy. Lancet 1979;2(8140):458-61.

23 Department of Health. Harold Shipman's clinical practice 19741998: a clinical audit commissioned by the Chief Medical Officer. London: Department of Health, 2001.

24 Luce T. Death certification and investigation in England, Wales and Northern Ireland -the report of a fundamental review. Norwich: The Stationery Office, 2003.

25 Baker J. The Shipman Inquiry Third Report: "Death certification and the investigation of deaths by coroners". Norwich: The Stationery Office, 2003 